\title{
Preparing Students for Studying Abroad
}

\section{Federica Goldoni ${ }^{1}$}

\begin{abstract}
This study is situated in the fields of language education, study abroad (SA) and intercultural communication. The interest in SA is increasing on the part of students, administrators, educators, and business companies for the learning opportunities that it offers. However, SA students are not always prepared to maximize their learning opportunities at the foreign site, to effectively interact with locals, to develop cultural awareness, and to respond to challenging situations occurring abroad. This article recommends preparatory activities to increase students' awareness and exercises on students' own identity as a powerful construct impacting their SA experiences. This article acknowledges that student preparation is only one aspect to be improved in the whole SA experience. Other structural and institutional issues of current SA programs need to be addressed too, including how to extent the length of the trips, how to diversify the destinations and the demographic profile of student participants, how to increase their autonomy, and ultimately how to train faculty and staff for change.
\end{abstract}

Key words: Cultural and linguistic immersion, foreign language education, study abroad, intercultural communication, identity

\section{Introduction}

The interest in study abroad (SA) remains strong and keeps increasing on the part of the students, small and large academic institutions in the US, educators and scholars, as well as business companies and firms that wish for universities to provide students with international education and awareness (Albers-Miller et al., 1999; IIE, 2014). The special issue on the impact of study abroad on retention and success by the Center for Global Education showed that SA appears to be more beneficial than domestic study in terms of language learning as it offers learning opportunities that are unmatched or unavailable at home. SA also teaches important lessons in terms of cultural knowledge and awareness (Asaoka, 2009; Marriott, 1993). Ongoing pressures push officials to evaluate SA and assess students' ability to effectively navigate in the target culture and society and function as informed interlocutors (Wilhelm, 2012).

This article suggests that SA students are not always linguistically and culturally prepared to optimize their learning opportunities at the foreign site. Students often struggle to become integrated in the host community, to negotiate the cultural differences that they encounter abroad (Block, 2007a), and to respond to challenging situations occurring at the intersection of two cultures. As a result, SA curricula should incorporate preparatory pedagogical components, as illustrated in this article. Such components are designed to reflect upon identity and SA, increase students' (self)awareness, improve their intercultural competence, enhance their linguistic and cultural abilities, and maximize their learning opportunities. This study is situated in the fields of applied linguistics, language education, and intercultural communication, and it addresses students, instructors, international education administrators and officials.

\footnotetext{
${ }^{1}$ School of Liberal Arts, Georgia Gwinnett College, 1000 University Center Lane, Lawrenceville, GA 30043, fgoldoni@ggc.edu.
} 


\section{Literature Review}

The latest statistics from IIE (2014) reveal important trends affecting SA. First, learning languages is not the main goal of international experiences anymore. Only 5\% of all US SA participants study world languages now (L2). The top six leading disciplines of Americans studying abroad are STEM fields (23\%), social sciences (22\%), business (20\%), humanities (10\%), and fine or applied arts (8\%). The tendency seems to downplay foreign language and culture learning, and to consider English as the official language for global communication. It is not unusual for SA participants to have to face situations in which interlocutors prefer to interact with them in English rather than in their first language in order to practice English. This may diminish the importance of learning L2, as Kubota (2002) suggested, and lead learners to believe that the role and significance of L2 study is marginal, a situation which does not play in favor of multilingualism and SA participation.

Second, short-term programs (typically summer programs, or eight weeks or less) serve the largest number of Americans studying abroad ${ }^{2}$. This trend affects students' opportunities to get involved and engaged into the local community, to be exposed to the various manifestations of the local culture, and to interact with locals. Other factors impact student engagement and authentic immersion and interaction abroad. Specifically, SA programs sponsored by US academic institutions typically act as in loco parentis. These programs provide 24/7 supervision, organize part of students' social time, assist them, and guarantee their physical, emotional, and psychological safety and well being. Moreover, US undergraduates in such programs go abroad in large groups. They are all placed in the same classes, and take home university credit-bearing courses taught by host- and home-university instructors who work, or at least are familiar, with US classroom norms, the US educational framework, and US grading systems. While abroad, US cohorts tend to express strong solidarity and build cohesive bonds. Scholars (Isabelli-García, 2006; Kline, 1998; 1993; Twombly, 1995) suggest that such group cohesion takes individual members away from a) acquiring L2; b) venturing out to explore new territories; and c) establishing contacts with local people.

Third, the typical US SA participants are middle-class Caucasian students (76\%). Their financial means often allow them to travel during and after the SA program, and they also receive multiple visits from friends and parents. However, ironically enough, these resources that allow them to have a travel agenda, also leave learners with little time for authentic language learning. It takes them away from practicing L2 and interacting with locals, and it prevents them from getting to know in depth and appreciating the local culture and society.

Along the same line, Block and Cameron (2002) warned that the ease of mobility and immediate access to communication technology make it possible for learners to participate in non-local networks, where geographical proximity or distance no longer matter. As a result, a good number of SA participants shy away from the pursuit of direct target language and culture learning, as well as face-to-face interactions with native speakers in their local communities. Block and Cameron also warned about the impact of consumerism on international education. It is not uncommon for US college students to view the experience of a global culture and

${ }^{2}$ Hackney et al. (2012) found that students in their study were more willing to study abroad on short-term programs rather than long-term, and females were more willing to study abroad shortterm than males. Journal of the Scholarship of Teaching and Learning, Vol. 15, No. 4, August, 2015. Josotl.Indiana.edu 
education abroad as a purchasable commodity, instead of as an investment and participation in L2-mediated activities with the host society. They picture the world as a big shopping center the "cultural supermarket” in Mathews' terms (2000), where they can satisfy most of their fantasies.

Finally, Kinginger (2008) found that the nature of learners' cultural and linguistic immersion experiences inside and outside of the classroom are interspersed with, and highly affected by social media, smart phones and tablets. For example, Deirdre, a young woman in France in Kinginger's study, retreated from all social interactions with French people in favor of online interactions with family and friends in the US. Such an "electronic umbilical cord" keeps learners away from various manifestations of the local culture.

The SA programs analyzed in this article reflected the general trends in US SA programs discussed above. What emerges from a broad review of the literature on SA, and is particularly relevant for this study as well, is that students do learn foreign languages in every dimension while abroad (Block, 2007b; Coleman, 2013; Kinginger, 2009, 2013). However, students’ identity (including nationality, social class, age, gender, race and ethnicity) and habitus using Bourdieu's words (1991) (i.e., ways of being and behaving), highly affect their language and culture learning experiences and opportunities, challenges, and outcomes (Kinginger, 2013). Some students strive and excel abroad, while others struggle. These considerable individual differences among students' learning experiences abroad may depend upon a) how learners invest their time at the foreign site (Freed, Segalowitz, \& Dewey, 2004); b) how they develop social networks and craft learning opportunities for themselves; c) how they are received by the local community and how they interpret the local practices and the various socio-cultural manifestations. Those students who founder typically struggle to negotiate the differences and deal with the discomfort and anxiety that they may experience as their identity, positioning, and habitus are challenged or questioned abroad. Faced with these disorienting situations, SA students typically withdraw from interaction with the host society and retreat into the protective environment represented by the SA group. It is clear that the US peer group functions as a powerful unifying element, a refuge to confirm and reinforce national identity and feelings of national superiority, and a place where students don't feel like outsiders. A possible consequence of this situation is the development of enhanced egocentrism, as discussed by Feinberg (2002). When interviewed and asked what they have learned after studying abroad, it is not uncommon for US students to answer "I learned a lot about myself," "the journey brought me face to face with myself," and "I have developed a great appreciation for my own culture.”

The ACTFL Standards for Foreign Language Learning offer guidance and advice is available to educators and students on how to prepare and maximize learners' sojourns abroad and engagement into the host community (see also Allen and Dupuy, 2012; Jackson, 2008; Kinginger, 2010; Paige et al., 2002a, 2002b). This article expands on this literature and incorporates elements examining the role of identity and the sense of self in relation to, and interaction with, the other and specific aspects of the foreign language and culture.

\section{The Study}

This article is the follow-up of a previous piece (Goldoni, 2013) that examined the multiple linguistic and cultural immersion experiences and learning opportunities that five groups of US undergraduates had during the 2007, 2008, and 2009 calendar years while participating in an

Journal of the Scholarship of Teaching and Learning, Vol. 15, No. 4, August, 2015. Josotl.Indiana.edu 
academic SA program in three cities in Spain: Colovo ${ }^{3}$ on the Levantine coast (13-week fall/spring programs) and Zadico and Villaro in the south (seven-week summer programs). The sponsor was a large public university in the Southeast offering intermediate- and advanced-level courses at these locations. This study, and the literature discussed above, revealed that SA students are not always adequately prepared from a linguistic, cultural and personal standpoint to take full advantage of their learning opportunities abroad and to become integrated in the host community. They often struggle when confronted with disorienting situations occurring abroad while interacting with locals and challenging subject positions. The present article offers relevant recommendations to students and educators and is guided by the following question: "What modules can help students prepare for SA?" The author claims that the exploration of students' own identity is the first step in this preparation process. Students' integration and engagement in the host community becomes truly successful when learners understand their individual and collective identity, and how it interacts with people from other cultures and societies.

What follows is a summary of the 2013 study, notably methods and findings. The discussion section presents preparatory pedagogical components that are designed to help prepare students for the SA journey.

\section{Participants, Programs of Study, Data Collection, and Data Analysis}

As detailed in Goldoni (2013), 160 college student participants were the main source of data collection. 44 of them (19-26 years) became the focal students (17 in Zadico, 20 in Colovo, and seven in Villaro). 98 additional people from both the host and home institutions were also part of this study, including faculty, staff, administrators, locals, and Spanish and international residence hall students. The programs of study were located in Colovo, Zadico and Villaro. In Colovo SA students shared rooms in a residence hall housing over 200 (inter)national students, and took courses taught by both home and host university faculty members. In Zadico and Villaro students resided with host families and took courses were taught by host university faculty members.

The main research question guiding this study was exploring the kind of cultural and linguistic immersion experiences that students have abroad and the effects on their identity. This study kept with ethnographic case study approaches in qualitative research (Bogdan \& Biklen, 2007; Holstein \& Gubrium, 1995, Merriam, 1998; Patton, 2002). Data were collected and analyzed during and after the programs (March 2007-August 2009). Semi-structured interviews (50 hours) were conducted in person, by telephone and via Skype with focal students, program and resident directors, academic coordinators, and graduate assistants. Interviews (up to three per participants) were audio-recorded, transcribed, and coded. The interview protocol covered the following areas of inquiry: a. The kind of linguistic, socio-cultural, and academic experiences that students had abroad; b. Any critical moment or challenge that students faced; c. How students responded to such experiences, and why; d. How such experiences impacted them, including their daily life abroad, academic performance, and interactions with locals; e. How students felt or wished at that point in the semester; g. Any additional comment that students wished to add. Observations (30 hours) and field notes covered classroom dynamics and activities, discussions, and course materials. Daily activities and 10 field trips (300 hours) were also observed, including students' interactions and experiences, and language use. Written

\footnotetext{
${ }^{3}$ Pseudonyms replace real names of people and sites. Journal of the Scholarship of Teaching and Learning, Vol. 15, No. 4, August, 2015. Josotl.Indiana.edu
} 
documents included students' logs, journals, postings on Facebook, emails, program evaluations, class assignments, and the SA program daily journals and reports (280 entries). Grounded theory (Glaser \& Strauss, 1967; Strauss \& Corbin, 1990) was used to inductively and recursively analyze the data. The audio-recorded interviews were transcribed and thematically analyzed using line-by-line coding. The rest of the data went through the same process. The author identified: a. The kind of students' experiences, reactions, and effects; b. The patters emerging from such experiences, reactions, and effects; c. the evidences and citations exemplifying such experiences, reactions, and effects. Vygotsky's socio-cultural theory (1978) was used to dig deeper into the students' cultural artifacts, social interactions, learning opportunities, agency and resourcefulness.

\section{Findings}

The five SA programs observed in Goldoni (2013) reflected the general trend in US SA programs discussed earlier: they were short-term programs acting as in loco parentis and offering a US educational setting abroad; most student participants were Caucasian undergraduates; English was the main language of communication within the large SA cohorts; and the opportunities for language and culture learning, exposure to manifestations of the local culture, and interaction with Spaniards were at times very modest, limited, and sporadic. As commented above, the differences among students' experiences in these five programs were striking. On one hand, some students were successful at finding strategies to practice the language, experience the culture, and interact with the host society. On the other hand, other students experienced the Spanish language and culture as a struggle, particularly when their identity and home culture were challenged, and they faced "rich points" (Agar, 1994), i.e., episodes of cross-cultural clash and miscommunication at the intersection of two cultures. Below is a collection of successful as well as challenging immersion stories abroad where the students' socio-cultural identity (including gender, age, race, ethnicity, and social class) shaped their experiences.

\section{Stories of Successful Immersion in the Host Society}

34 SA students described below experienced the Spanish culture and the language in an unprecedented way as they met and interacted with people of all ages from Spain and the Spanish-speaking world. Specifically, 15 male and female students in all three locations found Spanish boyfriends/girlfriends, or developed strong friendships with local native speakers. Through them they entered into a wide network of local contacts. Tree students decided to stay in, or return to, Spain and found a job after the SA program. Five students cultivated and deepened their interests and passions at the foreign site by a) joining the dorm soccer team; b) signing up for a flamenco dance class and joining a group of salsa dancers; c) attending a religious organization affiliated with their home church, and participating in various activities and excursions. Two students volunteered at a local non-profit organization offering sport activities to the local community and other free classes (ESL, computer, dance, and yoga classes).Finally, nine students reported memorable experiences with their host families, engaging in genuine conversations and dinner-table discussions that provided extended language practice and authentic exposure to local and family culture.

Journal of the Scholarship of Teaching and Learning, Vol. 15, No. 4, August, 2015. Josotl.Indiana.edu 
Stories of Cross-Cultural Conflicts.

The following accounts were taken from three specific SA students because they illustrate common themes that also surfaced for several students in the group. First, Albert was an AfricanAmerican student with an ardent interest in the Spanish language and culture and a special connection with it: His father was Dominican, as was his side of the family. However, Albert became alienated from the Spanish community following compelling incidents of what he perceived to be racial discrimination and injustice in Spain and Europe. Second, Theresa was a Caucasian upper-middle class student who found her Spanish instructor's comments and approach hurtful, a style she was unused to in the US where professors tend to be more nurturing and avoid overt criticism. This situation made Theresa feel uncomfortable and aggravated her already serious disengagement from academic learning. She saw SA as a vacation and an opportunity to extensive travel with other SA students in the contemporary "Grand Tour" tradition. Third, Rebecca was an attractive Caucasian undergraduate whose initial interest in the Spanish language and culture rapidly eclipsed after she experienced instances of male hostility towards US women as well as occasional but powerful episodes of machismo, male aggressive behavior, catcalling, and harassment toward herself, eight other female students from her SA cohort, and Spanish women including her two host mothers. Rebecca found these incidents appalling, became uncomfortable within the host community, and shied away from interacting with locals.

Spanish culture is fundamentally different from American culture, and the most significant differences emerging from this study are a) gender relations; b) interactions with people from different origin, race, and ethnicity; c) academic dynamics, responsibilities, and interactions; and d) instructor's role and status. The experiences narrated above of Albert, Rebecca, and Theresa presented common themes seen across the entire SA group. First, these students were unprepared to interact with the Spanish culture and society from a linguistic, cultural, and personal standpoint. Second, they were not provided with the tools to critically analyze the Spanish culture and to overcome their difficulties. In fact, they struggled to see their challenging experiences as an opportunity to explore cross-cultural differences in value systems and social practices. Confronted with episodes of cultural clash, these students interpreted and compared such events within the backdrop of their home culture. They took refuge in their US group and avoided consistent contact with locals as a reaction to their resentment and disappointment with the program and/or host culture that did not meet their expectations. Third, these students may not have acquired the experience or the (inter)personal abilities to be agentive (Vygotsky, 1978) and seriously invested in a learning process that may take different shapes and spins abroad. Finally, these students were not encouraged - nor required or trained - to become immersed with locals, negotiate meaning and establish durable contacts with them.

\section{Discussion}

A (summer) semester long SA program may not be long enough for the students to experience full linguistic and cultural immersion or develop intercultural competence, cultural awareness and effective communication. It is critical, therefore, to view SA as a year-long project when students take courses, participate in various projects, activities, and trainings, and receive Journal of the Scholarship of Teaching and Learning, Vol. 15, No. 4, August, 2015. Josotl.Indiana.edu 
guidance before, during, and after the program. The following section addresses the guiding question (What modules help students prepare for SA), and offers preparatory modules focusing on four main areas: a) Students' personal preparation for SA; b) Preparation for intercultural communication; c) Preparation for integration; and d) Linguistic preparation.

\section{Personal Preparation for SA}

The SA journey can be seen as a discovery of the self and the other. As observed by Kinginger (2013), it is advisable to focus on the students' identity construct first before any strategy for integration into, and interaction with, the host society can be recommended and implemented. A better understanding of how identity shapes students' SA experiences can help them approach, make sense of, and relate to the other and the multiple aspects of the foreign language, culture and society. The students participating in this study who struggled to remain open to difference, change, and connection with the other and the unknown could gain deeper self-awareness and knowledge of the self. The first step in this learning process is for the students to understand themselves as a product of their times, socio-cultural and geographical context. As articulated by Vygotsky (1987; 1986; 1978), we inherit, change, and pass on to future generations several cultural artifacts (ways of thinking, behaving, feeling, and expressing ourselves). These artifacts mediate our actions, perspectives and learning process. They make us unique and determine our identity. Pfeiffer discussed fourteen dimensions of diversity affecting identity: Age and gender, racial features and sexual orientation, ethnic culture and physical abilities (Pfeiffer, 1996: 14). Work background, marital status, military or travel experience, religious beliefs, geographic location, parental status, and education are the other powerful forces that forge our identity over time. The exercises below utilize these concepts to explore identity. They can be assigned to students before, during and/or after SA. Individualized feedback from the instructor is key to help students "unpack" their cultural identity and background.

\section{Cultural Autobiography.}

This activity is designed to help you analyze your own identity, life and upbringing from a cultural perspective:

a) Describe and analyze aspects of your life that have defined you as a person, and that have contributed to shaping your perspectives.

b) Identify salient characteristics in your life, including but not limited to your gender, age, ethnicity, social class, religious affiliation, sexual orientation, origin and geographic location, community, family role, profession, and education.

c) Discuss one influential person, or a critical event/moment, in your life which symbolically reflects your identity.

d) Use any visual representation when appropriate.

In this cultural autobiography, the key is depth rather than breadth.

\section{Cultural Background Pie.}

Journal of the Scholarship of Teaching and Learning, Vol. 15, No. 4, August, 2015.

Josotl.Indiana.edu 
This individual and group activity is intended to help you define who you are.

a) Answer the following questions: Who are you? What/who is important in your life, and why? What do you believe in? What made you believe the things you believe in? What is it in your background that makes you the person you are now?

b) Draw your own “cultural background pie” (Noel, 2008: 10). Each piece represents a significant element of your identity, gender, age, ethnicity, social class, religious affiliation, sexual orientation, origin and geographic location, community, family role, profession, and education. Each background pie is unique, despite the fact that they may look similar, because no individual feels exactly the same about his/her background and what has forged his/her identity.

c) Share your pie and thoughts with your classmates and instructor.

\section{Critical Incident/Transformative Experience.}

Every day we come in contact with individuals from different backgrounds, and we may have had a transformative experience:

a) Choose and present a critical incident or transformative experience.

b) Describe the context, who was involved, and what happened.

c) Critically analyze this incident/experience and say how it made you feel. If a particular cultural group is involved, then research their values, believes, and communicative behaviors. It will help you analyze the incident/experience.

d) Discuss the implications of this incident for your academic training, professional career, or future interactions.

e) Cite at least one reference.

Who am I?

\section{Gaining Self-Awareness and Knowledge of the Self.}

Reflect upon the following points, answer them, and explain why. Provide specific examples (adapted from Tarafdar, 2014).

a) How do I use language (apologizing, asserting, greeting, complimenting, approaching, (dis)agreeing, accepting, rejecting...)?

b) How do I use non-verbal behavior (eye-contact, touch, clothes, gestures, facial expressions...)?

c) How do I present information and organize messages in writing/speech (linear/circular, direct/indirect, expressive/restrained)?

d) How do I manage time (deadlines, decision-making...)?

e) How do I view leadership roles (making decisions, speaking in public, managing time and effort, delegating tasks, motivating and rewarding others...)?

f) How do I view relationships (women/men, boss/employee...)?

g) How do I establish trust and credibility?

Journal of the Scholarship of Teaching and Learning, Vol. 15, No. 4, August, 2015.

Josotl.Indiana.edu 
h) How do I view my own identity (gender, age, ethnicity, social class, religious affiliation, sexual orientation, origin and geographic location, community, family role, profession, and education)?

i) How do I talk to people from my community versus people from another community (using vs. avoiding slang, accenting and intonation, body language and hand gestures, listening vs. talking, lowering vs. rising the tone of the voice, asking for confirmation of understanding, clarifying meaning...)?

Who are we?

Cultural Stereotypes and Prejudices.

Reflect upon the following points, answer them, and explain why. Provide specific examples (adapted from Tarafdar, 2014).

a) What stereotypes have you learned from your friends and family?

b) What are some stereotypes of people from your ethnic group or community?

c) What is your way of categorizing people?

d) What stereotypes have you learned through the media?

e) What prejudice or intolerant disposition do you have toward another community of people?

\section{Preparation for Intercultural Communication}

After establishing the foundation of identity and determining one's core values and beliefs, students can approach more effectively the differences in people’s actions, practices, communication patterns, and behavior during cross-cultural interactions and intercultural dialogues. The students in this study who had an unsatisfactory intercultural communication experience had not acquired enough experience or tools to embrace the perspective of their interlocutors with empathy and a spirit of understanding and compassion. Activities and projects can be designed to help learners understand how their identity may interact in contact with other identities, and how one's behavior can be adapted to achieve desired goals.

\section{How Do We Talk To One Another? Knowledge of Difference.}

Reflect upon the following points, answer them, and explain why. Provide specific examples. a) How do other people from my community versus people from another community talk and communicate? (using vs. avoiding slang, accenting and intonation, body language and hand gestures, listening vs. talking, lowering vs. rising the tone of the voice, asking for confirmation of understanding, clarifying meaning...)

b) Are you truly listening to what other people are saying?

c) Do you fully understand the message conveyed and what your interlocutor(s) may imply/ask?

Journal of the Scholarship of Teaching and Learning, Vol. 15, No. 4, August, 2015. 
Tarafdar (2014) indicates that paraphrasing (restating a message to clarify and maintain the essential meaning) and empathy (the ability to understand the feelings of others and sympathize with them) are key to active listening and intercultural communication and competence. Paraphrasing and empathy help make interactions more effective and maintain relationships more solid. Students may be encouraged to do the following exercise for 30-60 days and practice empathy and paraphrasing as active listening skills.

\section{How Does It Feel To Be Like Them? \\ Perspective Taking: Empathy and Paraphrasing in Communication. (adapted from the Charmm'd Foundation)}

Show empathy during any emotional moment of a conversation. Summarize 2-3 key points discussed to gain understanding of the essential message conveyed. Then, each night reflect on the conversations you had during the day and write a journal: What went well? Why? Which strategies (clarifying, restating, neutral, reflecting, summarizing) did you use to make your conversation effective and to practice active listening skills? How did your interlocutor(s) respond? How could you improve your conversation?

Check all that apply:

$\square$ I have clarified the essential information conveyed.

$\square$ I have repeated the key points to build dialogue during the conversation.

$\square$ I have summarized the conversation and focused on the key points.

I have used sentences like... (check all that apply:

$\square$ Can you explain what you mean? $\square$ What I am hearing you say is... $\square$ If I understand correctly, you need... $\square$ You are frustrated because... $\square$ Can you tell me more? $\square$ I am sorry to hear about... $\square$ Can you confirm that we understand each other?

What can improve intercultural communication is knowledge and understanding of the various communication patterns as identified by Storti (2001), and how they may vary across cultures and from one person to another within the same culture.

\section{How Do We Improve Our Interactions?}

(adapted from Storti, 2001)

a) How would you describe your communication style? Linear or circular? Direct or indirect? Emotionally expressive or restrained? Concrete or abstract? Risk-taking or not?

b) Visually represent your communication style. Here is an example: A circular maze.

Journal of the Scholarship of Teaching and Learning, Vol. 15, No. 4, August, 2015. Josotl.Indiana.edu 
Goldoni, F.

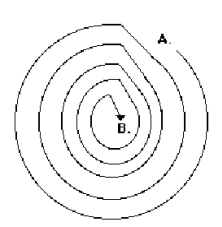

c) What can you do to adapt your communication style based on the person(s) you are interacting with?

d) Look at the strategies listed below to improve intercultural communication across styles. What strategies seem more effective to you? Why?

- Be patient; do not interrupt too quickly.

$$
\text { Linear Style } \rightarrow \text { Circular Style }
$$

- Listen and interpret.

- Make connections among elements.

- Remember that relationships matter.

$$
\text { Circular Style } \rightarrow \text { Linear Style }
$$

- If the response seems too brief, ask questions.

- Listen to synthesize and reformulate.

- Select what you will say, start with a linear statement, then add context and details.

- Look behind words.

Direct Style $\rightarrow$ Indirect Style

- Use metaphors that communicate the point.

- Think about the impact of the words you choose.

- Remember that relationships matter.

- Try not to feel attacked or targeted.

Indirect Style $\rightarrow$ Direct Style

- Remember to value directness and to take words seriously.

- Prefer facts to metaphors.

- Try to say exactly what you mean.

\section{Preparation for Integration Abroad}

Rich Points. The students in this study who struggled abroad tended to be anchored to their own ideas and values. They contextualized challenging events within the backdrop of their own identity and culture. Their learning process did not evolve from the ethnocentric stage in which "the worldview of one's own culture is central to all reality" (Bennett, 1993: 30). They did not switch to an ethnorelative perspective that may have allowed them to question their own responsibility and role in the events. Students seldom consider the possibility that they may encounter a "rich point" (Agar, 1994), a clash in cultural artifacts at the intersection of two cultures, a conflictive situation deserving of a more dispassionate investigation. The exercises below explore rich points and rely on assigned readings, pair/group discussions, and whole-class de-briefing.

SA in Spain: Rich Points.

Journal of the Scholarship of Teaching and Learning, Vol. 15, No. 4, August, 2015.

Josotl.Indiana.edu 
Read the stories of cultural clash occurred abroad in Goldoni (2013). Then, discuss the following point and explain why:

a) How and why this occurred.

b) How you would feel in a similar situation.

c) What you would do/say if you were in a similar situation.

d) What can be done to avoid such situations.

Instructors, together with any guest speaker or representative of the target culture, can help students approach intercultural conflicts or challenging experiences from a broader perspective, suspend judgment, and acknowledge that cultural practices are relative to one another in a specific socio-cultural context and time in history. Students should be encouraged to make connections between this activity and their cultural autobiography exercise or critical incident suggested above. This will help them better understand their identity and the nature of their feelings and perspectives.

Exploring the Host Country. Immersion abroad also means that SA students should act as "anthropologists" and conduct various forms of ethnographic inquiry such as researching the host country and society, its past and recent history, geopolitics, territory, economy, population, and customs.

\section{SA in Israel: What Do You Know About Israel?}

Research the host country. In particular, gather information about the points listed below ${ }^{4}$ :

Capital

Other cities

Bordering countries

Seas/oceans

Mountains

Rivers/lakes

Regions

Population
Important dates

Languages spoken

Colors of the flag

Famous people

Movies

Typical products

Government

President/Prime Minister
Social laws

Religion(s)

Climate

Currency

Exchange rate

Recent headline news

Newspapers

Channels/radios

Getting to Know the Host Family and Society. Instructors can promote engagement at the foreign site by helping students make the most of homestay or dormstay. The social networks allow students to get to know their host family before departure, and share photographs, common interests, favorite hobbies, likes and dislikes. Engle and Engle (1999) also suggest that students develop their friendship with a pen pal abroad before departure. They may also identify an interest they can cultivate abroad such as becoming part of a local sport team; joining a bike or a chess club; or taking a dance course or guitar lessons.

${ }^{4}$ Instructors can use and adapt this exercise in the target language.

Journal of the Scholarship of Teaching and Learning, Vol. 15, No. 4, August, 2015.

Josotl.Indiana.edu 


\section{SA in Italy: What Would You Do/Say To Your Host Family in These Situations?}

a) Imagine you are living with an Italian family who eats lots of pasta and bread every day. Carbohydrates are not your thing and you are afraid of gaining weight.

b) Your Italian host family has breakfast with just warm milk and cookies/croissants. You prefer an American breakfast. You miss peanut butter.

c) It is dinner time and your Italian host mom serves a dish that looks strange to you. You are reluctant to try it.

d) Your new Italian friends criticize American fast food.

Act out your dialogue in front of the class.

Do's and Don'ts. Instructors can discuss (un)recommended practices abroad and request that students maintain a journal at the foreign site where they annotate interesting habits, cultural manifestations, and practices that catch their attention or that may differ from their home culture or expectations ${ }^{5}$.

\section{SA in Jordan: Highly Recommended Cultural Practices.}

DO: Accept when Arabic coffee is offered to you by your host, as coffee is an important cultural symbol of hospitality, accepted as an act of reciprocated good will. When finished with your cup of coffee, shake your cup from side to side and let your host know that you do not wish to drink more. If more coffee is desired, then hold your cup out to the person carrying the coffeepot.

DO: Stand up when greeting others.

DO: Haggle with merchants when shopping.

SA in Jordan: Cultural Practices To Be Avoided.

DON'T initiate hand-shake with women. Wait until a woman extends her hand. If a hand is not extended, then a simple nod of the head or bow to acknowledge their presence is fine.

DON'T panic if an acquaintance "pecks" you on the cheeks when greeting you, as Arabs traditionally kiss each other on both cheeks as a warm gesture of welcome and affection.

DON'T feel uncomfortable if your host insists on "overfeeding" you, as Arabs traditionally view food as an important symbol of hospitality and generosity.

DON'T feel that you are required to tip your taxi driver, as tipping in such a scenario is not necessary, but it is certainly appreciated.

${ }^{5}$ Courtesy of Chernor Barrie instructor of Arabic at Queensborough Community College Journal of the Scholarship of Teaching and Learning, Vol. 15, No. 4, August, 2015. 
Ethnographic Inquiry within the Local Community. Instructors can encourage students to perform a "show and tell" presentation in class by sharing an object that tells something interesting about the local culture. Ethnographic inquiry can be promoted through observations, interviews, or surveys within the host community starting with host families, pen pals, or residence hall students. Another high-impact strategy to increase students' engagement is volunteer work and service learning at a local hospital, day care, tourist office, or non-profit organization.

\section{SA in France: Newspapers, Magazines, and TV Channels.}

Interview your host family members using Skype or other social media. Ask them...

a) What their favorite newspaper, magazine, and TV channels are, and why.

b) How often they read and watch TV.

c) If they get information from the internet.

d) How much money they spend per month to read, to watch TV, and to access the internet.

e) About their favorite newspaper section, program, or feature on TV/the internet.

\section{Linguistic Preparation.}

Instructors may help students prepare and act out responses in L2 for challenging situations such as catcalling or discriminatory behavior; conflict with the instructor on class performance/exam; episodes of misunderstanding with host family members; iPhone or iPad stolen; suitcase missing at the airport; and/or sudden illness. Reviewing survival expressions (and correct pronunciation) to get by in the host country is also essential. In their journal students can list colloquialisms, idioms, common phrases, interesting expressions, or curious ads. They should be given the basic linguistic tools to introduce themselves in L2 to their host families and other locals.

Do You Know How To Say These Things?

$\begin{array}{lll}\text { Good morning } & \text { Can you repeat? } & \text { Excuse me } \\ \text { Good afternoon } & \text { May I? } & \text { I'm sorry } \\ \text { Good night } & \text { Thank you } & \text { I apologize } \\ \text { Hello } & \text { You are welcome } & \text { I don't know } \\ \text { Bye } & \text { Nice to meet you } & \text { I don’t understand } \\ \text { See you later } & \text { How are you? } & \text { No / Yes }\end{array}$

SA Journal.

Journal of the Scholarship of Teaching and Learning, Vol. 15, No. 4, August, 2015. Josotl.Indiana.edu 
While abroad, journal about...

a) Interesting words/expressions you saw, read, and learned. Write something meaningful to contextualize what you have learned. Provide English equivalents. Add any visual representations.

b) An interesting ad or sign you found in the street, on TV, or in social media.

c) A recurrent expression you hear from your host family or other locals.

d) A word/expression that is particularly hard for you to pronounce.

e) An expression of politeness you are ready to use when appropriate.

What Would You Say To Locals When You Are...

a) ...in the street and need help to locate a specific place/building.

b) ....at the train station and want to purchase two tickets.

c) ....at the restaurant and want the bill.

d) ... at the hotel asking for recommendations about best/cheap restaurants in the area.

e) ....at the pharmacy. You are sick.

f) ....at the bank and need to exchange money.

g) .... at the post office and need to send a package.

h) ... at the outdoor market/fair and want to bargain prices.

l) ....at the police station to report an issue.

m) ...expressing (dis)agreement, happiness, sadness, acceptance/rejection, acknowledgment.

n) ...inviting a friend out.

\section{Self-Presentation. (see footnote 4)}

Prepare your self-presentation in L2. Customize the following model.

a) I am Laura, from NY, American, a student, single/in a relationship/married...

b) I am not tall/small, introvert/extrovert, sociable/reserved, optimistic/pessimistic...

c) I have a brother/sister, a boyfriend/girlfriend, two dogs/cats, three cars/bicycles...

d) I do not have any children, pets, siblings, money, relatives...

e) I like pasta, chocolate, animals, sports, cooking, dancing, going to the movies, travelling...

f) I do not like beer, wine, milk, fish, meat, eggs, golf, tennis...

\section{Implications and Conclusions}

This article acknowledges the structural and institutional issues of current SA programs in the US: short-term, hyper-supervised trips, predominantly middle-class Caucasian students, and classes are taught in a US educational setting abroad. English remains the students' main means

Journal of the Scholarship of Teaching and Learning, Vol. 15, No. 4, August, 2015. 
of communication, and their learning opportunities, exposure to the local culture, and interaction with locals are often limited. Therefore, these SA programs cannot claim full immersion as a realistic goal. Instead, they serve primarily as introductory programs facilitating US students' first exposure to the host community and first exploration of the target culture and society. As observed in this article, SA students remain fundamentally unprepared from a linguistic, cultural and personal standpoint to optimize their learning opportunities, to develop cultural awareness, and to respond to challenging situations occurring abroad. Therefore, preparatory courses, activities and projects like the ones suggested in this article are highly recommended, including exercises on students' own identity as a powerful construct impacting their SA experiences (Kinginger, 2013). Intensive and extensive reading of relevant literature on cultural awareness and intercultural communication are other important components of the academic program. Students can be encouraged to think and write about assigned topics, link direct experience and abstract understanding, and "enrich and extend authentic cultural experience through reflection, personal articulation, and practical advice” (Engle \& Engle 1999: 46) in class with their peers.

A sound discussion of high culture versus popular culture should be implemented in the curriculum. The programs that were observed in this study seemed more focused on high culture or "visible" culture. Students, however, seemed to need more exposure to popular culture, or "invisible culture," which is more challenging to them as it questions students' home culture and own identity. At times popular culture seemed hard for students to comprehend and it brought them out of their comfort zone. The role of the instructor in these contexts and discussions is to act as a facilitator of learning, serve as a guide, and assist students in acquiring knowledge, awareness, and sensitivity to certain questions, topics, and cross-cultural differences. In this environment, learners are prompted to develop genuine curiosity and respect for other people's practices and perspectives. Students can benefit from the opportunity to interact with various individuals from varied backgrounds, including guest speakers and host community members, and learn from each other. Sharing and comparing experiences and perspectives can contribute a great deal to the learning process of the group as a whole.

Preparing students for SA is only one part of a multi-faceted issue affecting international education. Substantial changes in SA programs can occur if the structural and institutional framework of SA is improved and re-imagined. For example, by offering short programs and sending students abroad in big groups to vacation spots, universities are fostering students' sense that SA is more of an extended vacation than a serious academic commitment and cultural encounter. This trend is eclipsing the potential of SA experiences as full cultural and linguistic immersion. University officials, offices of international education, and academic departments can rethink the SA experience at their institution and focus on a) how to diversify SA destinations; b) how to diversify the demographic profile of the SA population; c) how to extend the length of SA trips; d) how to increase the autonomy of SA student participants; and, e) how to prepare faculty and staff for change.

The IIE (2014) indicates that US students studied in increasing number of countries around the world, although English appears to be commonly spoken at these destinations and participants may not have to learn another language which makes their journey not as enriching from a linguistic standpoint. The five top destinations for US students remain the United Kingdom, Italy, Spain, France, China. However, other destinations in Asia are becoming popular, namely Thailand (+34\%), South Korea (+13\%), and Japan (+9\%). Latin America (Peru

Journal of the Scholarship of Teaching and Learning, Vol. 15, No. 4, August, 2015. Josotl.Indiana.edu 
$+10 \%$, Costa Rica $+8 \%$, Bazil $+4 \%)$ and South Africa (+18\%) are also hosting more US students.

Targeted outreach, recruitment, and funding can significantly increase minority participation in SA, and the IIE (2014) shows a growing number of African American (5.3\%), Asian/Pacific Islander (7.3\%), and Hispanic (7.6\%) students among SA participants. Fund raising and more scholarships can also help extend the length of SA programs, as well as experiential learning projects to be completed over several weeks or months, notably service learning, internships, and volunteer work abroad. These education abroad experiences can be truly transformative. An interesting topic for further research would be to compare white versus minority students and how they interpret and approach these SA tasks and influence and learn from each other. The need is also growing for individualized program features, components, and configurations to address different proficiency levels, backgrounds, social identities, expectations, and future plans.

The quality of pre-departure orientations and trainings for faculty, administrators, students and their families can be significantly improved. Faculty leaders should receive specific training on how to help students become more autonomous, independent, and agentive abroad, particularly if students have never before left the US or their state. These students could benefit from being paired with a more experienced mentor student or faculty member. The SA team should also include counselors and faculty members who are attuned to critical issues such as sexual harassment, race and ethnicity. Professionals should have experience working with students of color, and they should be able to offer strong support and mentorship. International collaborations and exchanges among faculty and institutions in the US and abroad are critical in this effort to improve the overall SA experience and educate students to become global citizens. More and more our multicultural, multiethnic and multilingual societies need translingually and transculturally competent individuals who can function as informed interlocutors. SA can contribute a great deal to this goal.

\section{References}

Albers-Miller, N., Prenshaw, P. J., Straughan, R. D. (1999). Student perceptions of study abroad programs: a survey of U.S. colleges and universities. Marketing Education Review, 9(1), 29-36.

Agar, M. (1994). Language shock: understanding the culture of conversation. New York: Morrow.

Allen, H. W., \& Dupuy, B. (2012). Study abroad, foreign language use, and the Communities Standard. Foreign Language Annals, 45, 4, 468-493.

Asaoka, T. (2009). The contribution of "study abroad” programs to Japanese internationalization. Journal of Studies in International Education, 13(2), 174-188.

Bennett, J. M. (1993). Cultural marginality: identity issues in intercultural training. In R. M. Paige (Ed.), Education for the intercultural experience (pp. 109-135). Yarmouth, ME: Intercultural Press.

Journal of the Scholarship of Teaching and Learning, Vol. 15, No. 4, August, 2015. Josotl.Indiana.edu 
Goldoni, F.

Block, D., \& Cameron, D. (2002). Globalization and language teaching. New York: Routledge.

Block, D. (2007a). The rise of identity in SLA research: post Firth and Wagner (1997). Modern Language Journal, 91, 863 - 876.

Block, D. (2007b). Second language identities. London: Continuum.

Bogdan, R., \& Biklen, S. K. (2007). Qualitative research for education: an introduction to theories and methods. Boston, MA: Pearson A \& B.

Bourdieu, P. (1991). Language and symbolic power. Cambridge, MA: Harvard University Press.

Center for Global Education. Impact of study abroad on retention and success. Retrieved on July 30, 2015 from http://globaledresearch.com/study-abroad-impact.asp.

Charmm'd Foundation. An exercise in active listening. Empathy and Paraphrasing. Retrieved on July 30, 2015 from http://www.charmmdfoundation.org/resource-library/activelistening/exercise-active-listening-empathy-paraphrasing.

Coleman, J. A. (2013). Researching whole people and whole lives. In C. Kinginger (Ed.), Social and cultural dimensions of language learning in study abroad. Amsterdam: John Benjamins.

Commission on the Abraham Lincoln Study Abroad Fellowship Program. (2005). Global competence and national needs: one million Americans studying abroad. Retrieved on July 30, 2015 from

http://www.nafsa.org/uploadedFiles/NAFSA_Home/Resource_Library_Assets/CCB/lincoln_co mmission_report\%281\%29.pdf?n=6097.

Engle, J., \& Engle, L. (1999). Program intervention in the process of cultural integration: the example of French practicum. Frontiers: the interdisciplinary journal of study abroad, 5, 39-60.

Falk, R., \& Kanach, N. (2000). Globalization and study abroad: an illusion of paradox. Frontiers: the Interdisciplinary Journal of Study Abroad, 4, 155-168.

Feinberg, B. (2002). What students don’t learn abroad. Chronicle of Higher Education. Retrieved on July 30, 2015 from http://chronicle.com/weekly/v48/i34/34b02001.htm.

Freed, B. F., Segalowitz, N., \& Dewey, D. P. (2004). Context of learning and second language fluency in French: comparing regular classroom, study abroad, and intensive domestic immersion programs. Studies in Second Language Acquisition, 26, 2, 275-301.

Glaser, B., \& Strauss, A. (1967). The discovery of grounded theory. Chicago: Aldine.

Goldoni, F. (2013). Students’ immersion experiences in study abroad. Foreign Language Annals, 46(3), 359-376.

Journal of the Scholarship of Teaching and Learning, Vol. 15, No. 4, August, 2015.

Josotl.Indiana.edu 
Goldoni, F.

Hackney,K., Boggs, D., Borozan, A. (2012). An empirical study of student willingness to study abroad. Journal of Teaching in International Business, 23, 123-144.

Holstein, J. A., \& Gubrium, J. F. (1995). The Active Interview. Qualitative Research Methods, Volume 37. London: Sage Publications.

Jackson, J. (2008). Language, identity and study abroad: sociocultural perspectives. London: Equinox.

IIE, Institute for International Education. (2014). Open doors report 2014. Retrieved on July 30, 2015 from http://www.iie.org/opendoors.

Isabelli-García, C. (2006). Study abroad social networks, motivation and attitudes: implications for second language acquisition. In M. A. DuFon \& E. Churchill (Eds.), Language learners in study abroad contexts (pp. 231-258). Buffalo: Multilingual Matters.

Kinginger, C. (2008). Language learning in study abroad: case histories of Americans in France. Modern Language Journal, Volume 92, Monograph. Oxford: Blackwell.

Kinginger, C. (2009). Language learning and study abroad: a critical reading of research. Basingstoke, UK: Palgrave/Macmillan.

Kinginger, C. (2010). Contemporary study abroad and foreign language learning: an activist's guidebook for language educators. University Park, PA: CALPER Publications.

Kinginger, C. (2013). Identity and language learning in study abroad. Foreign Language Annals, 46, 3, 339-358.

Kline, R. (1993). The social practice of literacy in a program of study abroad. Unpublished Dissertation. The Pennsylvania State University.

Kline, R. (1998). Literacy and language learning in a study abroad context. Frontiers, The International Journal of Study Abroad, 4, 139-165.

Kubota, R. (2002). The impact of globalization on language teaching in Japan. In D. Block \& D. Cameron (Eds.), Globalization and language teaching (pp. 13 - 28). New York: Routledge.

Marriott, H. E. (1993). Acquiring sociolinguistic competence. Australian secondary students in Japan. Journal of Asian Pacific Communication, 4(4), 176-192.

Merriam, S. B. (1998). Qualitative research and case study applications in education. San Francisco: Jossey-Bass Publishers.

Journal of the Scholarship of Teaching and Learning, Vol. 15, No. 4, August, 2015. Josotl.Indiana.edu 
Goldoni, F.

Mathews, G. (2000). Global culture/individual identity: searching for home in the cultural supermarket. New York: Routledge.

Noel, J. (2008). Developing multicultural educators. $2^{\text {nd }}$ ed. Long Grove, IL: Waveland Press.

Paige, R. M., Cohen, A. D., Kappler, B., Chi, J. C., \& Lassegard, J. P. (2002a). Maximizing study abroad: a program professionals' guide to strategies for language and culture learning and use. Minneapolis, MN: Center for Advanced Research on Language Acquisition, University of Minnesota.

Paige, R. M., Cohen, A. D., Kappler, B., Chi, J. C., \& Lassegard, J. P. (2002b). Maximizing study abroad: A students' guide to strategies for language and culture learning and use. Minneapolis, MN: Center for Advanced Research on Language Acquisition, University of Minnesota.

Patton, M. Q. (2002). Qualitative research and evaluation methods. Thousand Oaks, CA: Sage Publications.

Pfeiffer, J. W. (1996). The 1996 annual. Volume 2: consulting. San Diego, CA: Pfeiffer \& Company.

Senate Resolution 308. (2005, November 10). 2006, the year of study abroad. Retrieved on July 30, 2015 from http://www.gpo.gov/fdsys/pkg/BILLS-109sres308ats/pdf/BILLS109sres308ats.pdf.

Storti, C. (2001). The art of crossing cultures. Boston, MA: Intercultural Press.

Strauss, A., \& Corbin, J. (1990). Basics of qualitative research: Grounded theory procedures and techniques. Newbury Park, CA: Sage.

Tarafdar, M. (2014, 7 February). Improving intercultural communication. Presentation at Queensborough Community College.

Twombly, S. B. (1995). Piropos and friendship: gender and culture clash in study abroad. Frontiers: the Interdisciplinary Journal of Study Abroad 1, 1-27.

Vygotsky, L. S. (1978). Mind in society: the development of higher psychological processes. Cambridge, MA: Harvard University Press.

Vygotsky, L. S. (1986). Thought and language. Cambridge, MA: M.I.T. Press.

Vygotsky, L. S. (1987). Thinking and speech. In L. S. Vygotsky (Ed.), Collected works (Vol. 1, pp. 39-285). New York: Plenum.

Journal of the Scholarship of Teaching and Learning, Vol. 15, No. 4, August, 2015.

Josotl.Indiana.edu 
Goldoni, F.

Wilhelm, I. (2012, March 22). Study-abroad officials are under more pressure to prove their programs' value. Chronicle of Higher Education. Retrieved on July 30, 2015 from

http://chronicle.com/article/Study-Abroad-Officials-Are/131286/.

Journal of the Scholarship of Teaching and Learning, Vol. 15, No. 4, August, 2015.

Josotl.Indiana.edu 